\title{
EFEITOS DA TERRA DIATOMÁCEA SOBRE Diabrotica speciosa (GERMAR, 1824) (COLEOPTERA: CHRYSOMELIDAE) EM BATATA INGLESA
}

\author{
Effects of diatomaceous earth on Diabrotica speciosa (Germar, 1824) \\ (Coleoptera: Chrysomelidae) in potato
}

\author{
Franscinely Aparecida Assis' 1 , Jair Campos Moraes², Amanda Maria Nascimentoº Jonas Françoso² $^{2}$
}

\begin{abstract}
RESUMO
A espécie Diabrotica speciosa é um crisomelídeo responsável por causar danos consideráveis à batateira, o que torna indispensável seu controle com inseticidas para minimizar os prejuízos causados à cultura. Assim, objetivou-se, com este trabalho, avaliar os efeitos da terra diatomácea sobre o comportamento alimentar e a mortalidade de $D$. speciosa em batata inglesa em condições de laboratório. Adotou-se o DIC com três tratamentos e oito repetições, sendo: 1 - testemunha; 2 - TD polvilhada ( $0,5 \mathrm{~g} / \mathrm{vaso})$ e 3 TD pulverizada a 1\%. As batateiras, cv. Emeraude, foram polvilhadas ou pulverizadas com TD, 30 dias após o plantio e, 24 horas após a aplicação, as plantas foram fornecidas aos insetos, sem e com chance de escolha. Houve diferença significativa entre os tratamentos, sendo a menor porcentagem de folíolos com injúrias observada em plantas que receberam a aplicação de TD pulverizada (teste sem chance de escolha) e TD polvilhada ou pulverizada (teste com chance de escolha). Também houve redução do número de injúrias foliares às 24 e às 48 horas (TD polvilhada ou pulverizada) e, às 72 horas, a redução foi observada somente com a aplicação da TD polvilhada. Com relação à ação inseticida da TD, foi verificado seu efeito após 48 horas, tanto via polvilhamento, quanto via pulverização. Assim, a aplicação de TD pode auxiliar no manejo de D. speciosa, contribuindo para conferir proteção às plantas de batata inglesa e aumentar a mortalidade desse inseto-praga.
\end{abstract}

Termos para indexação: Insecta, dióxido de sílica, MIP.

\begin{abstract}
The species D. speciosa is a chrysomelid responsible for causing considerable damage on potato plant, making its control with insecticides essential to minimize the damage caused to this culture. The objective of this study was to evaluate the effects of diatomaceous earth (DE) on feeding behavior and mortality of D. speciosa in potato under laboratory conditions. A completely randomized design was used with three treatments and eight replicates being: 1 - control; 2 - sprinkled DE (0.5 g/vase) and 3 - $1 \%$ sprayed DE. The potato plants, cv. Emeraude, were sprinkled or sprayed with DE 30 days after the planting and 24 hours after the application, the plants were supplied to insects, with and without a chance of choice. There was significant difference among treatments with a lower leaflet with injury percentage observed in plants that received the application of powdered DE (tests without chance of choice) and sprinkled or powdered DE (tests without chance of choice). There was also reduction of the number of leaf injuries at 24 and 48 hours (sprinkled or powdered DE) and, at 72 hours, the reduction was only observed with the application of sprinkled DE. Regarding the insecticidal activity of TD, its effect was verified after 48 hours, through sprinkling or spraying. As a result, the application of DE may help in the management of $D$. speciosa, contributing to provide protection to potato plants and to increase the mortality of this insect pest.
\end{abstract}

Index terms: Insecta, silicon dioxide, IPM.

(Recebido em 20 de março de 2010 e aprovado em 14 de setembro de 2010)

\section{INTRODUÇÃO}

A espécie Diabrotica speciosa (Germar, 1824) (Coleoptera: Chrysomelidae) é um besouro que, na fase adulta, é conhecido popularmente como vaquinha, patriota ou brasileirinho, devido à coloração de seu corpo. A larva é denominada de larva alfinete, por apresentar o corpo alongado e fino (Gassen, 1986).

No Brasil, esse crisomelídeo tem sido registrado em culturas como milho (Marques et al., 1999), batata (Salles \& Grutzmacher, 1999; Lara et al., 2004), entre outras, demonstrando ser uma praga polífaga. Levantamentos populacionais realizados em diferentes genótipos de batateira demonstram que esse inseto predomina como praga chave da cultura na safrinha (Grutzmacher \& Link, 2000). Os danos e injúrias provocados por D. speciosa em batateira variam em função da fase do inseto-praga, uma vez que as larvas, de hábito subterrâneo, provocam orifícios nos tubérculos e, na fase adulta, consomem a área foliar das plantas (Lara et al., 2004; Silva et al., 2010).

Dentre as formas de controle que podem ser empregadas para $D$. speciosa, citam-se a adoção de genótipos

\footnotetext{
'Universidade Federal de Lavras/UFLA - Departamento de Entomologia - Cx. P. 3037 - 37200-000 - Lavras, MG - franscinelyagronomia@yahoo.com.br 2Universidade Federal de Lavras/UFLA - Departamento de Entomologia - Lavras, MG
} 
que expressem algum mecanismo de resistência (Lara et al., 2000, 2004; Salles, 2000) e o uso de produtos químicos. Contudo, muitas vezes, o uso de inseticidas é feito sem levar em consideração os possíveis fatores que influenciam a incidência de pragas de solo (Salles, 2000). Assim, inseticidas do grupo dos carbamatos (Mikami \& Ventura, 2008), fosforados (Salles \& Grutzmacher, 1999), neonicotinóides (Gomes et al., 2008) e piretróides (Alleoni et al., 2001) são empregados para o controle de D. speciosa, promovendo a contaminação dos cursos de água, e afetando o meio ambiente e organismos não-alvo.

Uma opção ao uso de inseticidas é a utilização da terra diatomácea, que é um sedimento amorfo originado de carapaças de organismos unicelulares vegetais, como algas microscópicas aquáticas, constituído principalmente por sílica (58-91\%) (Meisiner, 1981). Essa terra tem sido utilizada, em várias pesquisas, como agente de controle de pragas de grãos armazenados (Pinto Júnior et al., 2005; Ceruti et al., 2008; Pinto Júnior, 2008). Como inseticida, esse produto afeta o balanço hídrico do inseto, causando abrasão no tegumento e a morte por desidratação (Banks \& Fields, 1995; Palyvos et al., 2006).

A terra diatomácea também exerce efeito sobre o comportamento dos insetos, uma vez que atua como repelente sobre adultos de Alphitobius diaperinus (Panzer, 1797) (Coleoptera: Tenebrionidae) (Alves et al., 2008; Oliveira et al., 2009), Sitophilus oryzae (L., 1763) (Coleoptera: Curculionidae), Tribolium castaneum (Herbst., 1797) (Coleoptera: Tenebrionidae) e Cryptolestes ferrugineus (Stephens, 1831) (Coleoptera: Cucujidae) (Mohan \& Fields, 2002). Além disso, o silício tem apresentado efeito positivo no manejo de pragas em culturas de batata (Gomes et al., 2009), trigo (Costa et al., 2007), soja (Moraes et al., 2009), entre outras, como um complemento ao controle químico.

Pelo exposto, objetivou-se, com este trabalho, avaliar os efeitos da terra diatomácea sobre o comportamento alimentar e a mortalidade de $D$. speciosa em batata inglesa em condições de laboratório.

\section{MATERIAL E MÉTODOS}

Efeito da terra diatomácea aplicada em plantas de batata inglesa sobre Diabrotica speciosa

O experimento foi conduzido no Laboratório de Resistência de Plantas a Insetos, no Departamento de Entomologia da Universidade Federal de Lavras (UFLA), em Lavras, MG, no período de janeiro a outubro/2009.

O plantio das batateiras foi realizado em vasos com $3 \mathrm{~kg}$, utilizando-se como substrato solo (Latossolo Vermelho
Escuro) adubado com $3 \mathrm{~g}$ do adubo NPK (4-14-8) por vaso, equivalente a $2 \mathrm{t} / \mathrm{ha}$, e uma batata-semente cv. Emeraude/ vaso. Os vasos foram mantidos sobre bancadas no interior da câmara climatizada com temperatura de $30^{\circ} \mathrm{C}$ durante o dia e $25^{\circ} \mathrm{C}$ à noite, umidade relativa de $70 \pm 10 \%$ e fotofase de 12 horas. Após 30 dias do plantio, foram realizados o desbaste e o tutoramento das plantas com bambu, deixando-se duas hastes da batateira/vaso.

A coleta de adultos de $D$. speciosa foi realizada em cultura de feijoeiro, com o auxílio de sugador de plástico acoplado a recipiente de vidro. Posteriormente, esses coleópteros foram levados para o laboratório, onde foram mantidos, por 24 horas, em gaiola de acrílico 30x30x80 cm, e alimentados em plantas de batateira, cv. Emeraude, cultivadas em vasos.

Adotou-se o delineamento inteiramente casualizado, com três tratamentos e oito repetições. Os tratamentos foram: T1 - testemunha; T2 - terra diatomácea $\left(\right.$ Insecto $\left.^{\circledR}\right)$ polvilhada na dosagem de $0,5 \mathrm{~g} /$ vaso e T3 solução a $1 \%$ de terra diatomácea (Insecto ${ }^{\circledR}$ ) pulverizada na dosagem de $50 \mathrm{~mL} /$ vaso. A solução a $1 \%$ foi preparada diluindo-se $0,5 \mathrm{~g}$ de terra diatomácea em $50 \mathrm{~mL}$ de água. Para o polvilhamento da TD sobre as hastes da batateira, foi utilizada uma peneira de plástico de $15 \mathrm{~cm}$ de diâmetro e, para a pulverização da solução, um pulverizador manual com capacidade para 1,5 L, até que a solução escorresse pelas folhas e hastes das plantas.

No teste sem chance de escolha, os vasos foram individualizados aleatoriamente em bancada e cobertos com tecido organza apoiado em duas hastes de bambu fixadas no substrato do vaso, formando uma gaiola de aproximadamente $20 \mathrm{~cm}$ de diâmetro e $60 \mathrm{~cm}$ de altura. Foram liberados 10 adultos/gaiola 24 horas após a aplicação dos tratamentos e, decorridos 10 dias da infestação, avaliouse a porcentagem de folíolos com injúrias.

No teste com chance de escolha, 24 horas após a aplicação dos tratamentos, foram liberados 240 adultos de D. speciosa no interior da sala climatizada. Decorridos 10 dias das infestações, foi avaliado a porcentagem de folíolos com injúrias.

\section{Ação inseticida da terra diatomácea sobre Diabrotica speciosa}

As gaiolas, para este ensaio, foram confeccionadas com seção de tubo de PVC, com $10 \mathrm{~cm}$ de altura e $9,5 \mathrm{~cm}$ de diâmetro, sobre placa de Petri de $13,5 \mathrm{~cm}$ de diâmetro, revestida com um círculo de papel de filtro. No interior das gaiolas, foram colocados cinco folíolos da batateira, retirados dos vasos referentes a cada tratamento, em um tubo de $2 \mathrm{~cm}$ de diâmetro e $5 \mathrm{~cm}$ de altura, contendo água 
para manter a umidade. A parte superior da gaiola foi fechada com tecido de organza fixado com um elástico. Foram liberados cinco adultos/gaiola, sendo os folíolos substituídos após 24 horas.

Avaliaram-se o número de injúrias nos folíolos e a porcentagem de mortalidade acumulada após 24, 48 e 72 horas.

\section{Análise estatística}

Os dados foram submetidos à análise de variância e as médias comparadas pelo teste de Scott-Knott $(p \leq 0,05)$, sendo os dados de mortalidade transformados em arcoseno $\sqrt{\mathrm{X} / 100}$ antes da análise.

\section{RESULTADOS E DISCUSSÃO}

\section{Efeito da terra diatomácea aplicada em plantas de batata} inglesa sobre Diabrotica speciosa

Verificou-se que houve diferença significativa entre os tratamentos em relação à porcentagem de injúrias foliares no ensaio sem chance de escolha, sendo observado mais que o dobro nas plantas não tratadas (testemunha) e nas polvilhadas com terra diatomácea, quando comparadas com as plantas pulverizadas (Tabela 1).

Possivelmente, a aplicação da terra diatomácea, por meio de um pulverizador permitiu uma cobertura mais homogênea das plantas em relação ao seu polvilhamento com peneira plástica, o que pode ter reduzido a alimentação do inseto.

De maneira semelhante, no teste com escolha, observou-se que, para os diferentes tratamentos, também a utilização da terra diatomácea, seja na forma polvilhada $(24,6 \pm 4,16)$ ou pulverizada $(25,7 \pm 6,18)$, diferiu significativamente das plantas não tratadas, conferindo mais que o dobro de proteção, quando comparadas com a testemunha $(56,4 \pm 4,30)$ (Tabela 1$)$.

Com relação às injúrias, em ambos os testes, a utilização de terra diatomácea reduziu as perfurações nos folíolos de batateira, apesar de, em outras condições experimentais, Bavaresco (2007) não ter observado injúrias causadas por Acanthoscelides obtectus (Say, 1831) (Coleoptera: Bruchidae) em feijão armazenado, possivelmente devido ao contato extremo dos carunchos com a terra diatomácea na massa de grãos. Portanto, os efeitos dessa substância sobre os insetos foram mais contundentes que os observados nesta pesquisa.

Tabela 1 - Porcentagem de folíolos injuriados (média \pm EP) por $D$. speciosa, em plantas de batata inglesa submetidas a diferentes tratamentos em teste sem e com chance de escolha (temperatura: $30^{\circ} \mathrm{C}$ durante o dia e $25^{\circ} \mathrm{C}$ à noite, umidade relativa de $70 \pm 10 \%$ e fotofase de 12 horas).

\begin{tabular}{lcc}
\hline \multirow{2}{*}{ Tratamento } & \multicolumn{2}{c}{$\%$ de Folíolos com Injúrias } \\
\cline { 2 - 3 } & Teste sem chance & Teste com chance \\
\hline Testemunha & $47,5 \pm 6,08 \mathrm{a}$ & $56,4 \pm 4,30 \mathrm{a}$ \\
TD polvilhada & $36,9 \pm 9,54 \mathrm{a}$ & $24,6 \pm 4,16 \mathrm{~b}$ \\
TD pulverizada & $17,9 \pm 2,37 \mathrm{~b}$ & $25,7 \pm 6,18 \mathrm{~b}$ \\
\hline
\end{tabular}

Médias seguidas da mesma letra na coluna não diferem estatisticamente entre si, pelo teste de Scott-Knott $(\mathrm{p} \leq 0,05)$.

\section{Ação inseticida da terra diatomácea sobre Diabrotica speciosa}

Pode-se observar que houve diferença significativa dos tratamentos em relação ao número de injúrias foliares às 24,48 e 72 horas e também para a porcentagem de mortalidade acumulada às 48 horas, comprovando alguma ação inseticida da terra diatomácea (Tabela 2).

A utilização da TD, seja na forma polvilhada ou pulverizada, contribuiu para reduzir a alimentação do crisomelídeo durante as primeiras 48 horas. Contudo, após 72 horas, o número de injúrias foliares foi reduzido em, no mínimo, três vezes, com o uso da TD polvilhada $(0,9 \pm 0,32)$,

Tabela 2 - Número de injúrias foliares e porcentagem de mortalidade acumulada (média土EP) de D. speciosa em batata inglesa submetida a diferentes tratamentos (temperatura: $30^{\circ} \mathrm{C}$ durante o dia e $25^{\circ} \mathrm{C}$ à noite, umidade relativa de $70 \pm 10 \%$ e fotofase de 12 horas).

\begin{tabular}{lrrrrrr}
\hline Tratamento & NIF 24h & NIF 48h & NIF 72h & PMA 24h* & PMA 48h & PMA 72h* \\
Testemunha & $6,2 \pm 1,17 \mathrm{a}$ & $4,4 \pm 0,75 \mathrm{a}$ & $4,1 \pm 1,01 \mathrm{a}$ & $2,5 \pm 2,49$ & $10,0 \pm 5,34 \mathrm{~b}$ & $22,5 \pm 9,58$ \\
TDPolvilhada & $1,1 \pm 0,31 \mathrm{~b}$ & $1,2 \pm 0,22 \mathrm{~b}$ & $0,9 \pm 0,32 \mathrm{~b}$ & $12,5 \pm 7,49$ & $35,0 \pm 6,27 \mathrm{a}$ & $42,5 \pm 7,01$ \\
TDPulverizada & $2,1 \pm 0,30 \mathrm{~b}$ & $2,7 \pm 0,62 \mathrm{~b}$ & $2,8 \pm 0,40 \mathrm{a}$ & $10,0 \pm 6,54$ & $22,5 \pm 7,00 \mathrm{a}$ & $30,0 \pm 6,54$ \\
\hline
\end{tabular}

NIF- Número de injúrias foliares (5 folíolos de batata/gaiola); PMA- Porcentagem de mortalidade acumulada. Médias seguidas da mesma letra na coluna não diferem estatisticamente entre si, pelo teste de $\mathrm{Scott}-\mathrm{Knott}(\mathrm{p} \leq 0,05)$. *Não significativo pelo teste F ( $\mathrm{p}>0,05)$. 
se comparado aos demais tratamentos. Possivelmente, a pulverização da TD promoveu maior degradação do produto, enquanto o seu polvilhamento manteve a sua atividade por mais tempo. Com relação à porcentagem de mortalidade acumulada, somente foi observado efeito significativo dos tratamentos após 48 horas da aplicação.

Vários trabalhos comprovaram o efeito inseticida da TD (Pinto Júnior et al., 2005; Bavaresco, 2007; Ceruti et al., 2008) quando a aplicação foi por meio de polvilhamento do produto diretamente na massa de grãos armazenados, o que dificulta as possíveis comparações com os resultados desta pesquisa.

De maneira geral, os resultados obtidos demonstraram que a terra diatomácea pode constituir uma alternativa viável no controle de $D$. speciosa em batateira, podendo acarretar redução de alimentação até causar mortalidade. Contudo, embora a mortalidade de pragas de grãos armazenados submetidas à TD seja atribuída à dessecação da cutícula do inseto, esse mecanismo não está bem elucidado neste estudo.

\section{CONCLUSÕES}

A aplicação de terra diatomácea em folhas de batateira afeta o comportamento de $D$. speciosa, reduzindo a alimentação do inseto-praga.

A terra diatomácea apresenta ação inseticida sobre adultos de D. speciosa.

\section{REFERÊNCIAS BIBLIOGRÁFICAS}

\section{ALLEONI, B.; SOUZA NETO, A.M.; WIECHETECK,} E.H. Eficiência das formulações $50 \mathrm{CS}$ e $250 \mathrm{CS}$ do inseticida Karate no controle de Diabrotica speciosa (Germar, 1824) (Coleoptera - Chrysomelidae) na cultura do feijoeiro (Phaseolus vulgaris L.). Revista

Ecossistema, Espírito Santo do Pinhal, v.26, n.2, p.129132, ago./dez. 2001.

ALVES, F.A.; OLIVEIRA, D.G.P.; NEVES, P.M.O.J. Fatores que afetam a eficiência da terra diatomácea no controle de adultos de Alphitobius diaperinus (Panzer) (Coleoptera: Tenebrionidae). Neotropical Entomology, Londrina, v.37, n.6, p.716-722, nov./dez. 2008.

BANKS, H.J.; FIELDS, P.G. Physical methods for insect control in stored-grain ecosystems. In: JAYAS, D.S.; WHITE, N.D.G.; MUIR, W.E. Storedgrain ecosystems. New York: M. Dekker, 1995. p.353-409.
BAVARESCO, A. Avaliação de tratamentos alternativos para o controle do Acanthoscelides obtectus (Say) (Coleoptera: Bruchidae). Revista de Ciências Agroveterinárias, Lages, v.6, n.2, p.125-133, 2007.

CERUTI, F.C.; LAZZARI, S.M.N.; LAZARRI, F.A.; PINTO JUNIOR, A.R. Eficácia de terra diatomácea e temperatura para o controle do gorgulho-do-milho em milho armazenado. Scientia Agraria, Curitiba, v.9, n.1, p.73-78, jan./mar. 2008.

COSTA, R.R.; MORAES, J.C.; ANTUNES, C.S.

Resistência induzida em trigo ao pulgão Schizaphis graminum (Rondani, 1852) (Hemiptera: Aphididae) por silício e acibenzolar-S-methyl. Ciência e Agrotecnologia, Lavras, v.31, n.2, p.393-397, mar./abr. 2007.

GASSEN, D.N. Manejo de pragas associadas à cultura do milho. Passo Fundo: EMBRAPA-CNPT, 1986. Folheto.

GOMES, F.B.; MORAES, J.C.; ASSIS, G.A. Silício e imidacloprid na colonização de plantas por Myzus persicae e no desenvolvimento vegetativo de batata inglesa. Ciência Rural, Santa Maria, v.38, n.5, p.12091213, ago. 2008.

GOMES, F.B.; MORAES, J.C.; NERI, D.K.P. Adubação com silício como fator de resistência a insetos-praga e promotor de produtividade em cultura de batata inglesa em sistema orgânico. Ciência e Agrotecnologia, Lavras, v.33, n.1, p.18-23, jan./fev. 2009.

GRUTZMACHER, A.D.; LINK, D. Levantamento da entomofauna associada a cultivares de batata em duas épocas de cultivo. Pesquisa Agropecuária Brasileira, Brasília, v.35, n.3, p.653-659, mar. 2000.

LARA, F.M.; POLETTI, M.; BARBOSA, J.C. Resistência de genótipos de batata (Solanum spp.) a Diabrotica speciosa (Germar, 1824) (Coleoptera, Chrysomelidae). Ciência Rural, Santa Maria, v.30, n.6, p.927-931, nov./ dez. 2000.

LARA, F.M.; SCARANELLO, A.L.; BALDIN, E.L.L.; BOIÇA JÚNIOR, A.L.; LOURENÇÃO, A.L. Resistência de genótipos de batata a larvas e adultos de Diabrotica speciosa. Horticultura Brasileira, Brasília, v.22, n.4, p.761-765, out./dez. 2004. 
MARQUES, G.B.C.; ÁVILA, C.J.; PARRA, J.R.P. Danos causados por larvas e adultos de Diabrotica speciosa (Coleoptera: Chrysomelidae) em milho. Pesquisa Agropecuária Brasileira, Brasília, v.34, n.11, p.19831986, nov. 1999.

MEISINER, A.C. Diatomite, mineral commodity summaries. New York: USGS, 1981. 47p.

MIKAMI, A.Y.; VENTURA, M.U. Isca amilácea de cucurbitacina (Lagenaria vulgaris L.) promove maior eficiência do inseticida carbaril no controle de Diabrotica speciosa, em laboratório. Ciência Rural, Santa Maria, v.38, n.8, p.2119-2123, nov. 2008.

MOHAN, S.; FIELDS, P.G. A simple technique to assess compounds that are repellent or attractive to storedproduct insects. Journal of Stored Products Research, Oxford, v.38, n.1, p.23-31, Jan. 2002.

MORAES, J.C.; FERREIRA, R.S.; COSTA, R.R. Indutores de resistência à mosca-branca Bemisia tabaci biótipo $\mathrm{B}$ (Genn, 1889) (Hemiptera: Aleyrodidae) em soja. Ciência e Agrotecnologia, Lavras, v.33, n.5, p.1260-1264, set./out. 2009.

OLIVEIRA, D.G.P.; ALVES, L.F.A.; MARCHESE, L.P.C.; THOMAZONI, D. Persistência da ação inseticida e repelência da terra de diatomácea para o cascudinho-dos-aviários Alphitobius diaperinus (Panzer, 1797) (Coleoptera: Tenebrionidae). Semina: Ciências Agrárias, Londrina, v.30, n.1, p.201-210, jan./ mar. 2009.
PALYVOS, N.E.; ATHANASSIOU, C.G.;

KAVALLIERATOS, N.G. Acaricidal effect of a diatomaceous earth formulation against Tyrophagus putrescentiae (Astigmata: Acaridae) and its predator Cheyletus malaccensis (Prostigmata: Cheyletidae) in four grain commodities. Journal of Economic Entomology, Berlin, v.99, n.1, p.229-236, Jan. 2006.

PINTO JÚNIOR, A.R. Eficiência de terra diatomácea no controle de algumas pragas de milho armazenado a granel. Revista da Faculdade de Zootecnia, Veterinária e Agronomia, Uruguaiana, v.15, n.1, p.61-70, 2008.

PINTO JÚNIOR, A.R.; LAZARRI, F.A.; LAZARRI, S.M.N. Controle de Acanthoscelides obtectus (Coleoptera: Bruchidae) com diferentes doses de terra diatomácea (dióxido de sílica). Revista Acadêmica: Ciências Agrárias e Ambientais, Curitiba, v.3, n.1, p.75-79, jan./mar. 2005.

SALLES, L.A.B. Incidência de danos de Diabrotica speciosa em cultivares e linhagens de batata. Ciência Rural, Santa Maria, v.30, n.2, p.205-209, mar./abr. 2000.

SALLES, L.A.B.; GRUTZMACHER, A.D. Eficiência do inseticida clorpirifós no controle de larvas de Diabrotica speciosa (Germ.) (Coleoptera: Chrysomelidae) na cultura da batata. Ciência Rural, Santa Maria, v.29, n.2, p.195199, mar./abr. 1999.

SILVA, V.F. da; MORAES, J.C.; MELO, B.A. Influence of silicon on the development, productivity and infestation by insect pests in potato crops. Ciência e Agrotecnologia, Lavras, v.34, n.6, p.1465-1469, nov./dez., 2010. 